\title{
THE HUMAN HIP STRESS ANALYSIS: A BALL-SOCKET ELASTIC CONTACT MODELLING
}

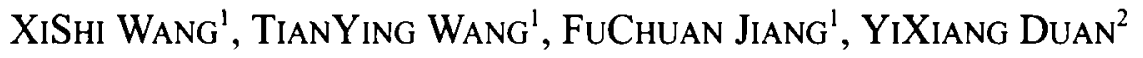 \\ 'Dept of Mathematics and Physics, QingDao Institute of Architecture and Engineering \\ ${ }^{2}$ Dept of Orthopaedics, QingDao Hospital, QingDao, P.R.China
}

\begin{abstract}
The peak stress, the weight bearing area and the stress distribution of the articular contact at the human hip joint is the most important factors, which determine the location of the degenerative foci that later result in degenerative damage and in the development of osteoarthritis. In the paper, a ball-socket articular elastic contact modelling of the human hip joint is successfully established. This modelling can be used to predict the peak stress, the weight bearing area and the stress distributions of the articular contact at the human hip joint. In order to verify the validation of current modelling, an example is examined. The results show that the predictions from the current modelling are basically agreement with those reported in literatures. This shows the validity of the current modelling.
\end{abstract}

Biomed Eng Appl Basis Comm, 2004(October); 16: 233-237.

Keywords: Hip, modelling, peak stress, weight bearing area, stress distribution

\section{INTRODUCTION}

The hip joint is one of the biggest ball-socket and bcaring-weight joint in the human body [1]. The clinical research shows that the hip joint appears particularly vulnerable to osteoarthrosis, and the evidence suggests conditions which increase contact stresses also substantially reduce its durability [2-4]; on the other hand, procedures to reduce contact stresses may improve its longevity [5-7]. It is well recognized that the intrinsic pathomechanical changes in the hip joint depend upon local stress levels rather than upon global joint loading. Therefore, the estimation of hip joint contact stress is very useful for

Received: Mar 3, 2004; Accepted: Aug 28, 2004

Correspondence: Wang XiShi, Professor

Dept of Mathematics and Physics

Qingdao Institute of Architecture and Engineering

No.11, FuShun Rd., QingDao, 266033, P. R. China

E-mail: wang_xishi@hotmail.com both preoperative planning and postoprerative rehabilitation. In addition, it is also very helpful to know the hip contact stress distributions for better understanding the mechanics of the normal and pathologic hip joint.

Basically, there are two ways to approach hip contact stress distributions. One is an experimental approach, including directly [8-11] or indirectly [1213] hip contact stress measurements. The newer experimental approach uses the thin pressure sensitive film [14]. Certainly, these measurements give insight into the features of the hip. However, these measurements can only obtain contact stresses at the discrete locations, rather than overall. Even as pressure sensitive films, there are still some problems, but are typically thicker, the spherical nature of the hip would obviously create problems for flat sensors. Other is an analytic [15-24], either numerical or using finite element models [25-27].

The earlier modellings to study hip joint contact stresses were static and semi-qualitative [15-17]. Such models took into account statically estimated loads; approximate joint surface areas, determined average 
stresses, and then estimated stress distribution onto a planar projection of a joint. Although these approaches illustrated important concepts, they did not contribute materially to knowledge of actual stress levels or distribution. The recent modellings to study hip joint contact stress are based on an important assumption, which adopted a cosine function form as the stress distribution at the hip joint [18-24]. With regard to the contact finite element modelling [25-27], although they provide complete stress distributions, however, it is always difficult and time consuming in analyzing a three dimensional model. Therefore this method is not suitable to acquire information for treatment in individual case.

In this paper, the classical elastic contact theory [28-30] will be employed to study the peak stress, the contact stress distributions and the contact area at the hip joint. Firstly a ball-socket (hip head-acetabulum) articular elastic contact modeling at the hip joint is established. The femoral head and the acetabular shell are taken to be spherical, while the thickness of the cartilage layer before the deformation is assumed to be constant. Then the classical contact theory [28-30] is applied to analyze the peak stress, the contact stress distributions and the contact area at the hip joint. The results show that the present modelling predictions are basically agreement with those reported in the literatures.

\section{METHODS}

\subsection{Geometric Relationships on the Modelling}

The coordinate system for ball-socket elastic contact modelling at the hip joint is constructed as shown in Fig. 1. The initial contact point $O$ between the femoral head and the acetabulum acts as the origin of the rectangular Cartesian coordinate system. The coordinate system is oriented so that the $\boldsymbol{x}-\boldsymbol{y}$ plane is the public tangent one of the two contact surfaces; while the $z$-axis is perpendicular to the public tangent plane and through the centers of contact surfaces. The acetabulum is described as a hemisphere concave (socket) contact surface with the radius $\boldsymbol{R}_{l}$, while femoral head is described as a hemisphere convex (ball) one with the radius $\boldsymbol{R}_{2}$. It is assumed that the articular cartilage is a homogenous and linear elastic solid with a uniform thickness. And it is assumed that the frictional force between the femoral head and acetabulum is neglected since the fact of synovia in the hip joint [31]. The elastic modulus and Poisson ratios for the articular cartilages of the acetabulum and the femoral head are, respectively, $E_{1}, \mu_{1}$, and $E_{2}, \mu_{2}$. The point $\boldsymbol{m}$ and $\boldsymbol{n}$ (see Fig.1) are two arbitrary points on the two hemispherical surfaces, which are very close to the public tangent plane, and the distance from the point $\boldsymbol{m}$ and $\boldsymbol{n}$ to the $\boldsymbol{z}$ axis is $\boldsymbol{r}$. While the distances from the public tangent plane to the points are, respectively, $z_{1}$ and $z_{2}$. Thus, we have

$$
\left\{\begin{array}{l}
\left(R_{1}-z_{1}\right)^{2}+r^{2}=R_{1}^{2} \\
\left(R_{2}-z_{2}\right)^{2}+r^{2}=R_{2}^{2}
\end{array}\right.
$$

Or

$$
\left\{\begin{array}{l}
z_{1}=\frac{r^{2}}{2 R_{1}-z_{1}} \\
z_{2}=\frac{r^{2}}{2 R_{2}-z_{2}}
\end{array}\right.
$$

It is because of the fact that points $\boldsymbol{m}$ and $\boldsymbol{n}$ are very close to the public tangent plane, thus we have,

$$
\left\{\begin{array}{l}
2 R_{1}-z_{1} \approx 2 R_{1} \\
2 R_{2}-z_{2} \approx 2 R_{2}
\end{array}\right.
$$

Furthermore, the equation (2) can be rewritten as following,

$$
\left\{\begin{array}{l}
z_{1}=\frac{r^{2}}{2 R_{1}} \\
z_{2}=\frac{r^{2}}{2 R_{2}}
\end{array}\right.
$$

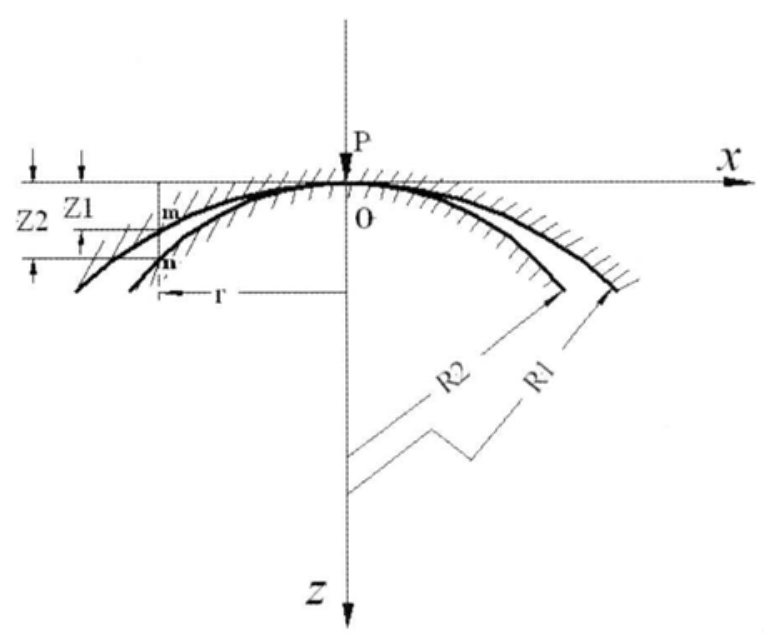

Fig 1. The coordinate system for the ball-socket elastic contact modelling. 


$$
\begin{aligned}
& \text { Or } \\
& z_{2}-z_{1}=\frac{r^{2}}{2}\left(\frac{1}{R_{2}}-\frac{1}{R_{1}}\right)=\frac{R_{1}-R_{2}}{2 R_{1} R_{2}} r^{2}
\end{aligned}
$$

If the displacements of the points $\boldsymbol{m}$ and $\boldsymbol{n}$ at the $\boldsymbol{z}$ axis direction are, respectively, $\boldsymbol{w}_{1}$ and $\boldsymbol{w}_{2}$, then the shorten quantity between any two points at the $z$-axis, $\boldsymbol{\delta}$, can be written as following,

$$
\delta=z_{2}-z_{1}+w_{1}+w_{2}
$$

Substituting Eq.(5) into (6), we have,

$$
w_{1}+w_{2}=\delta-\beta r^{2}
$$

where $\beta=\frac{R_{1}-R_{2}}{2 R_{1} R_{2}} \quad$. This is the displacement equation or geometric relationship of the ball-socket elastic contact modelling at the hip joint.

\subsection{Physical Relationships and Equilibrium Equations on the Modelling}

It is assume that the displacement at any point $M$ on the contact area is $\boldsymbol{w}$ due to the contact pressures. If the element area is taken as $s d \varphi d s$, here the $s$ is the distance from the point $M$ to the element area, while the $\varphi$ is the angle between the secant line through the point $\mathrm{M}$ and the oy axis (see Figure 2 ). Then, the contact pressure acting on the element area can be written as following,

$$
q s d \varphi d s
$$

where the $q$ is the contact pressures on the contact area.

Thus, according to the Boussinesq Problem's solutions [30], the displacement at any point $M$ due to the pressures $q . s d \varphi d s$ can be written as following,

$$
w=\frac{1-\mu^{2}}{\pi E} \iint_{A} q d \varphi d s
$$

If the two elastic bodies contact each other, then we have,

$$
\left\{\begin{array}{l}
w_{1}=\frac{1-\mu_{1}^{2}}{\pi E_{1}} \iint_{A} q d \varphi d s \\
w_{2}=\frac{1-\mu_{2}^{2}}{\pi E_{2}} \iint_{A} q d \varphi d s
\end{array}\right.
$$

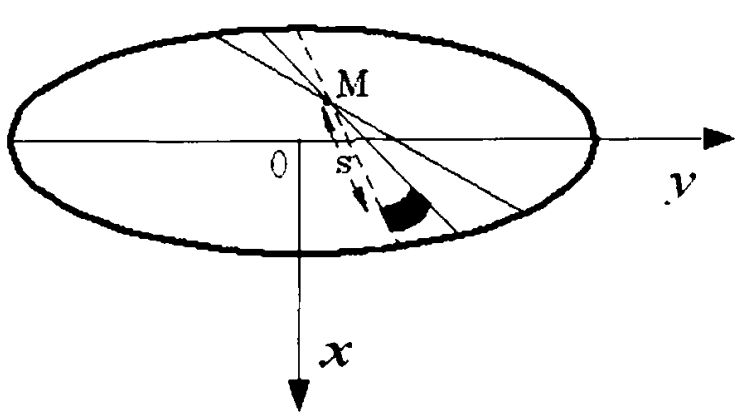

Fig 2. The coordinate system for calculating pressures on the contact area.

where the $A$ is the elastic contact area.

Substituting Eq.(9) into (7), we have,

$$
\left(k_{1}+k_{2}\right) \iint_{A} g d s d \varphi=\delta-\beta r^{2}
$$

where $k_{1}=\frac{1-\mu_{1}^{2}}{\pi E_{1}}, k_{2}=\frac{1-\mu_{2}^{2}}{\pi E_{2}}$.

It is because of the fact that the elastic contact area between the hip head and acetabulum is the circular one, therefore, at the boundary of the contact area, the following relationship must be held,

$$
w_{1}+w_{2}=0
$$

Thus, from Eq.(7) or (10), the radii of the elastic contact area can be determined as following,

$$
r_{\mathrm{c}}=\sqrt{\delta / \beta}
$$

The integral equation (10) can be solved by the inverse method. The results are given as following:

$$
\left\{\begin{array}{l}
r_{c}=\left[\frac{3 \pi P\left(k_{1}+k_{2}\right) R_{1} R_{2}}{4\left(R_{1}-R_{2}\right)}\right]^{1} \\
q_{0}=\frac{3 P}{2 \pi r_{r^{2}}{ }^{2}} \\
q(\zeta, \eta)=\frac{3 P}{2 \pi r_{c}{ }^{2}}\left(1-\frac{r^{2}}{r_{c}{ }^{2}}\right)^{\frac{1}{2}}, r^{2}=\zeta^{2}+\eta^{2} \\
\delta=\frac{3 \pi P\left(k_{1}+k_{2}\right)}{4 r_{c}}
\end{array}\right.
$$

Where the $r_{c}$ is radii of the contact area; the $q_{0}$ is the maximum contact stress; the $q$ is the stress distributions of the contact area; the $P$ is the resultant force acting on the hip joint. 


\section{RESULTS}

In the previous section, a ball-socket contact elastic modelling of the human hip joint was successfully established. On other words, if the radius and the material constants of the human femoral head and acetabulum and the resultant force acting on the hip are known, the peak stress and stress distributions and the articular contact area can be directly determined from Eq. (13). At the following, as an example, the formulae are examined. The parameter values are taken as following[32]:

$$
R_{I}=25 \mathrm{~mm}, R_{2}=24 \mathrm{~mm},
$$

$$
E_{l}=E_{2}=2.989 \mathrm{GPa}, \quad \mu_{1}=\mu_{2}=0.29
$$

$$
P=70 \mathrm{Kg}
$$

Then from Eq (13), we have,

$$
\begin{aligned}
& r_{c} \approx 5.74 \mathrm{~mm} \\
& q_{0} \approx 9.74 \mathrm{MPa}
\end{aligned}
$$

$$
q=(\zeta, \eta)=\frac{3 P}{2 \pi r_{C}{ }^{2}}\left(1-\frac{r^{2}}{r_{C}{ }^{2}}\right)^{\frac{1}{2}}
$$

It is, in the case, that the peak stress and the radii of the articular elastic contact at the human hip joint are, respectively, $9.74 \mathrm{MPa}$ and $5.74 \mathrm{~mm}$. While, the stress distributions of the articular contact area at the hip joint is determined by the $\mathrm{Eq}$ (14). Basically, these results are basically agreement with those reported in the literatures for peak contact stress, such as [33]: $10 \mathrm{MPa}$; [34]: 4.9-9.6; [35]: 6-10MPa; [36]: 7.5$9.0 \mathrm{MPa}$; etc. This shows the validity of the current modelling.

\section{DISCUSSIONS}

The peak stress, the weight bearing area and the stress distributions of the articular contact at the human hip joint are thought to be most important factors, which determine the location of the degenerative foci that later result in degenerative damage and in the development of osteoarthritis. However, so far these key factors are, mainly, determined by measured in vitro or vivo. It is noticeable that the human bone is inhomogeneous. And also, the mechanical properties of bone are different due to the age, race, sex, dry bone and fresh bone etc. Therefore, it is necessary to develop a predictive modelling for clinical practice. In this paper, a ball-socket articular contact elastic modelling of the human hip joint was successfully established. This modelling can be used to predict the peak stress, the weight bearing area and the stress distributions of the articular contact at the human hip joint. As a test for the validation of modelling, an example is examined. The results show that the predictions from the current modelling are basically agreement with those reported in literatures. This shows the validity of the current modelling.

\section{ACKNOWLEDGEMENT}

This work is supported by Natural Science Foundation of ShanDong Province in China(Grand No. Y2003C01).

\section{REFERENCES}

1. Mao BinRao: The Surgery of Hip Joint. The People's Health Press, Beijing: 1998, p5-56.

2. Brinckmann P, Frobin W, Hierholzer E. Stress on the articular surface of the hip joint in healthy adults and persons with idiopathic osteoarthrosis of the hip joint. J Biomech 1981; 14 (3): 149-56.

3. Hadley NA, Brown TD, Weinstein SL. The effects of contact pressure elevations and aseptic necrosis on the long-term outcome of congenital hip dislocation. J Orthop Res 1990; 8 (4): 504-13.

4. Olson SA, Bay BK, Hamel A. Biomechanics of the hip joint and the effects of fracture of the acetabulum. Clin Orthop 1997; 339: 92-104.

5. Iglic A, Kralj-Iglic V, Antolic V, Srakar F, Stanic U. Effect of the periacetabular osteotomy on the stress on the human hip joint articular surface. IEEE Trans Rehab Eng 1993; 1 (4): 207-12.

6. Srakar F, Iglic A, Antolic V, Herman S. Computer simulation of periacetabular osteotomy. Acta Orthop Scand 1992; 63 (4): 411-2.

7. Vengust R, Daniel M, Antolic V, Zupanc O, Iglic A, Kralj-Iglic V. Biomechanical evaluation of hip joint after Salter innominate osteotomy: a longterm follow-up study. Arch Orthop Trauma Surg 2001; 121: 511-6.

8. Rushfeldt, P.D., Mann, R.W., Harris, W.H. Improved techniques for measuring in vitro the geometry and pressure distribution in the human acetabulum II. Instrumented endoprosthesis measurements of articular surface pressure distribution. Journal of Biomechanics. 1981(14); 315-323. 
9. Brown, T.D., Shaw, D.T. In vitro contact stress distributions in the natural human hip. Journal of Biomechanics. 1983(16); 373-384.

10. Brown TD, Shaw DT. A technique for measuring instantaneous in vitro contact stress distributions in articular joints. J Biomech 1982; 15 (4): 329-33.

11. Armstrong CG, Bahrani AS, Gardner DL. In vitro measurement of articular cartilage deformations in the intact human hip joint under load. J Bone Joint Surg (Am) 1979; 61 (5): 744-55.

12. Hodge, W.A., Fijan, R.S., Carlson, K.L., Burgess, R.G., Harris, W.H., Mann, R.W. Contact pressures in the human hip joint measured in vivo. Proceedings of the National Academy of Sciences of the USA 1986(83), 2879-2883.

13. Hodge, W.A., Carlson, K.L., Fijan, R.S., Burgess, R.G., Riley, P.O., Harris, W.H., Mann, R.W. Contact pressures from an instrumented hip endoprosthesis. Journal of Bone and Joint Surgery, 1989(71 A); 1378-2883.

14. Polliack AA, Sieh RC, Craig DD, Landsberger S, McNeil DR, Ayyappa E. Scientific validation of two commercial pressure sensor systems for prosthetic socket fit. Prosthet Orthot Int 2000; 24 (1): 63-73.

15. Pauwels F.: Die struktur der tangentialfaserschicht des gelenkknorpels der schulterpfanne als beispiel fur ein verkorpertes spannungsfeld. Z Anat Entwicklungsgesch. 1959; 121: 188-240.

16. Pauwels $F$. Biomechanics of the normal and diseased hip: Theoretical foundations, technique, and results of treatment, 276. Berlin: SpringerVerlag; 1976.

17. Maquet P. Le sourcil cotylidien, materialisation du diagramme des contraintes dans l'articulation de la hanche. Acta Orthop Belg 1974; 40: 150-65.

18. Iglic A, Kralj-Iglic V, Antolic V, Srakar F, Stanic U. Effect of the periacetabular osteotomy on the stress on the human hip joint articular surface. IEEE Trans Rehab Eng 1993; 1 (4): 207-12.

19. Iglic A, Kralj-Iglic V, Antolic V. Reducing the stress in the articular surface of the hip joint after shifting the upper part of the body towards the painful hip. Acta Chir Orthop Traumatol Czech 1994; 61: 268-70.

20. Daniel M, Antolic V, Iglic A, Kralj-Iglic V. Determination of contact hip stress from nomograms based on mathematical model. Med Eng Phys 2001; 23 (5): 347-57.

21. Ipavec M, Brand RA, Pedersen DR, Mavcic B, Kralj-Iglic V, Iglic A. Mathematical modelling of stress in the hip during gait. J Biomech 1999; 32 (I1): 1229-35.
22. Mavcic B, Antolic V, Brand R, Iglic A, Kralj-Iglic $V$, Pedersen DR. Peak contact stress in human hip during gait. Pflugers Arch 2000; 440 (5): R177-8.

23. Ipavec M, Iglic A, Iglic VK, Srakar F. Stress distribution on the hip joint articular surface during gait. Pflugers Arch 1996; 431 (6): R275-6.

24. Iglic A, Antolic V, Srakar F. Biomechanical analysis of various operative hip joint rotation center shifts. Arch Orthop Trauma Surg 1993; 112 (3): 124-6.

25. Rapperport, D.J., Carter, D.R., Schurman, D.J. Contact finite element stress analysis of the hip joint. Journal of Orthopaedic Research, 1985(3), 345-446.

26. Brown, T.D., Pedersen, D.R., Baker, K.J., Brand, R.A. Mechanical consequences of core drilling and bone-grafting on osteonecrosis of the femoral head. Journal of Bone and Joint Surgery, 1993(75A), 1358-1367.

27. Dalstra, M., Huiskes, R., 1995. Load transfer across the pelvic bone. Journal of Biomechanics, 1995(28), 715-724.

28. Johnson, K.L. Contact Mechanics, Cambridge University Press, London, 1985.

29. Qian, W.Chan, Elastic Theory. Chinese Science and Technical Press, Beijing, 1955.

30. Timoshenko S, Translated by Xu ZhiLun: Elasticity Theory. People's Education Press, Beijing, 1990.

31. Shrive, N.G., Frank, C.B.. Articular cartilage. In: Nigg, B.M., Herzog, W.(Eds.), Biomechanics of the Musculo-Skeletal System. Wiley, Chichester, 1995, pp. 79-105.

32. Wang YiJing, Wang JieLin. Bone Biomechanics. The PLA Medicine Press, Beijing, 1989: 276-279.

33. Brown TD, Ferguson AB, Jr. The effects of hip contact aberrations on stress patterns within the human femoral head. Ann Biomed Eng 1980; 8 (1): 75-92.

34. Adams D, Swanson SA. Direct measurement of local pressures in the cadaveric human hip joint during simulated level walking. Ann Rheum Dis 1985; 44 (10): 658-66.

35. Maxian TA, Brown TD, Weinstein SL. Chronic stress tolerance levels for human articular cartilage: two nonuniform contact models applied to longterm follow-up of CDH. J Biomech 1995; 28 (2): 159-66.

36. Hak DJ, Hamel AJ, Bay BK, Sharkey NA, Olson SA. Consequences of transverse acetabular fracture malreduction on load transmission across the hip joint. J Orthop Trauma 1998; 12 (2): 90-100. 